\title{
Validation of Hydraulic brakes for Electric Vehicles
}

\author{
Verónica Flores Sánchez, Arely Vallejo Heráncez, Carlos A. Ventura de la \\ Paz, Jesús Juárez Borbonio
}

Department of IMI, Universidad Tecnológica del Centro de Veracruz, Veracurz, México

Email:

\begin{abstract}
This document shows the validation of the hydraulic brakes occupied in a solar electric vehicle. The braking system evaluated consists of two components: the brake pedal with master cylinder and the wheel brake mechanism, together with the corresponding tubes or conduits and the clamping pieces.

This validation is carried out through the analysis of forces, in the first part the braking force between the tire and the floor is determined; subsequently the force is calculated in the main braking system which is activated by a pedal

The braking system with which it is suitable for the prototype in question is that of a Volkswagen sedan, because this brake system meets the needs of drivers in terms of efficiency.
\end{abstract}

Keywords-Prototype, validation, brake system.

\section{INTRODUCTION}

The braking system is an indispensable device for the safety of the driver, for years it has evolved implementing different methods to improve its performance, however the method of hydraulic braking has been one of the most effective and efficient, has had some modifications in its form of application, but in general it has continued to operate by the pascal principle which says that the pressure exerted in a closed system is the same in all directions and directions.

\section{Objective}

Design brakes for an electric vehicle for urban use.

\section{Methodol ogy}

For the analysis of the braking system, the braking system of a Volkswagen sedan will be considered since it is an efficient braking system and matches the characteristics of the vehicle being made.

The calculations are based on the braking system of Figure 1, since this system has been performed in other vehicles and has delivered good results in its operation.

The current situation of the company was investigated through surveys carried out with engineers and workers from different areas, and the results obtained by the company's laboratory were analyzed.

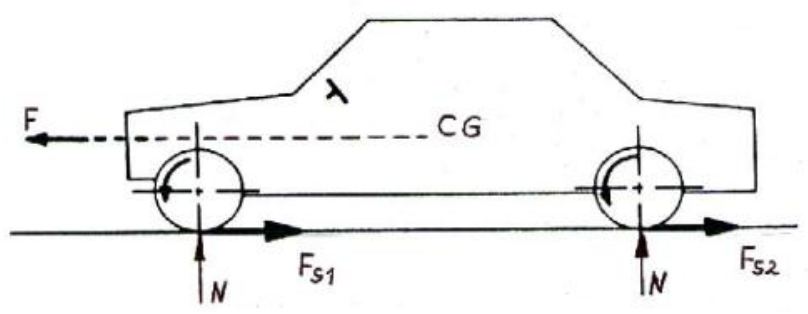

Fig.1: Friction forces retaining the movement of the car.

It is estimated a maximum speed of the prototype is 75 $\mathrm{km} / \mathrm{h}$, whose mass is $980 \mathrm{Kg}$.

Braking forces between the tire and the floor.

When the surfaces in contact between two bodies are perfectly smooth, the forces of interaction of the bodies always act in a direction normal to the surface at the points of contact. However, all surfaces are actually rough and it depends on the nature of the problem to be considered and on the ability of a body to withstand tangential and normal forces on its contact surfaces. The tangential force is caused by friction.

In cars, a force Fs of resistance acting on the tires acts which prevents or retards its sliding in relation to the surface or ground with which you are in contact between the tire-floor and is directed in such a way that it opposes the Possible or existing movement of the wheel in relation to these points.

In the friction of the wheel, the resistance is caused by the interference of small deformations or grooves formed when rolling one surface over another.

We must take into account that the forces of friction produced by the wheel's adhesion to the ground allow the tires to roll or the car to move on the ground, since the force $\mathrm{F}$ applied to the center of gravity of the vehicle that circulates on the ground has to be greater than the friction force in friction between tire-plane, that is, that F> Fs the car moves, otherwise if the force Fs> F the car is not move to.

In the case of braking, that is to say when the brakes are applied through the actuating pedal exerted by the driver, the vehicle is retained by the friction forces Fs 1 and Fs 2 
between the pneumatic floor since the force $\mathrm{F}$ is less than the friction force between the wheel and the floor.

The force of friction is directly proportional to the force that the wheel is subjected to on the floor and can be calculated:

$\mathrm{Fs}=\mathrm{N} * \mu \mathrm{S}$

Data:

$\mu \mathrm{S}=$ is the friction between the two surfaces in pneumatic-ground contact is measured by the static friction coefficient $\mu \mathrm{S}$, which is the coefficient between the friction force and the $\mathrm{N}$ of the force that the tire is subjected to on the ground.

Table 1 shows the values of the adhesion coefficient $\mu$ s.

Table.1: Adhesion coefficient values

\begin{tabular}{|l|c|c|c|}
\hline \multirow{2}{*}{ Type of ground } & Condition & New tire & $\begin{array}{c}\text { Used } \\
\text { tire }\end{array}$ \\
\hline \multirow{3}{*}{ Concrete } & Dry & 1 & 1 \\
\cline { 2 - 4 } Thick as phalt & Wet & 0.7 & 0.5 \\
\hline \multirow{4}{*}{ Normal asphalt } & Dry & 1 & 1 \\
\cline { 2 - 4 } & Wet & 0.7 & 0.5 \\
\hline \multirow{3}{*}{ Compact asphalt } & Dry & 0.6 & 0.6 \\
\cline { 2 - 4 } & Wet & 0.5 & 0.3 \\
\cline { 2 - 4 } & Mud & 0.2 & 0.1 \\
\cline { 2 - 4 } & Wee & 0.05 & $<0.05$ \\
\hline
\end{tabular}

Due to the mass of the vehicle, the force applied to each tire is $2403.45 \mathrm{~N}$.

According to table 1 the friction force is:

Dry Normal Asphalt: 0.6

$\mathrm{Fs}=(2403.45 \mathrm{~N})(0.6)=1442.07$

Wet Normal Asphalt: 0.5

Fs $=(2403.45 \mathrm{~N})(0.5)=1201.725$

Braking force in the main brake systems.

The main brake system is activated by a pedal located inside the vehicle, by the driver. The effort exerted on the pedal is transmitted to the braking elements Zapata, tabor or disc through a hydraulic circuit, in which a master cylinder or brake pump is available where the pressure in the liquid is generated, which is transmitted by the pipes to the wheel cylinders that drive the shoes or pads.

Braking force in the control of the main hydraulic brake circuit.

The pressure that is to be applied to the brake pads or pads is achieved, first, by the mechanical effort by the pedal lever and under the pressure of the driver's foot.

The brake pedal consists of the lever that applies the pressure of the foot, turns on its axis transmitting the effort to the pump, in the direction of F1, the spring 2 allows the pedal to return to its initial position when the driver stops 'Press the brake pedal.

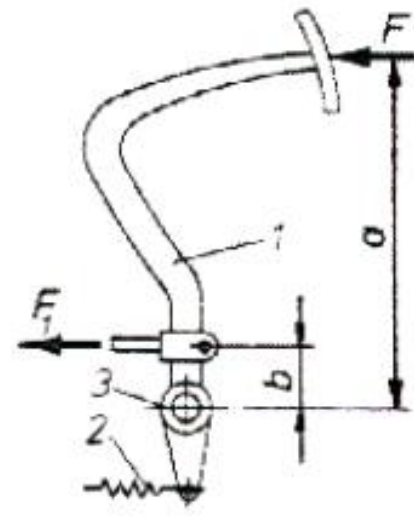

Fig.2: Forces on the brake pedal.

In Figure 2, the force F1 exerted on the piston rod of the brake pump is calculated from the effort $\mathrm{F}$ performed by the driver on the pedal, the latter force was measured based on tests with the dynamometer applied to a Volkswagen sedan car whose result when applying the force on the pedal to achieve compression was: $107.91 \mathrm{~N}$, similarly the data based on the distances were obtained from the same type of vehicle.

Data obtained:

$\mathrm{a}=20 \mathrm{~cm}=0.06 \mathrm{~m}$

$\mathrm{b}=0.6 \mathrm{~cm}=0.27 \mathrm{~m}$

$\mathrm{F}=107$.

$\mathrm{F} 1=(\mathrm{F} * \mathrm{a}) / \mathrm{b}$

To solve the unknown, we substitute the data in equation 2 and we have:

$\mathrm{F} 1=((107 \mathrm{~N}) *(0.2 \mathrm{~m})) / 0.06 \mathrm{~m}=356,666 \mathrm{~N}$

As the $\mathrm{F} 1$ force in the hydraulic circuit it is important to determine the pressure PB exists in the brake pump which is equal to:

DATA:

$\dot{\mathrm{F}} 1=356,666 \mathrm{~N}$

(Ø1) $2=$ Diameter of the master cylinder is: $2.21996 \mathrm{~cm}$ $=0.0221996 \mathrm{~m}$

$\mathrm{p}_{-}(\mathrm{B}=\mathrm{F} 1 /(\varnothing \ldots(/ 4) \wedge(2 * \pi))) \mathrm{pB}=356.66 /$ $0.0221996 * 3.14 / 4=50,473,119 \mathrm{~N} / \mathrm{m} 2$

With $\emptyset 1$ the diameter of the plunger of the brake pump of figure 3 .

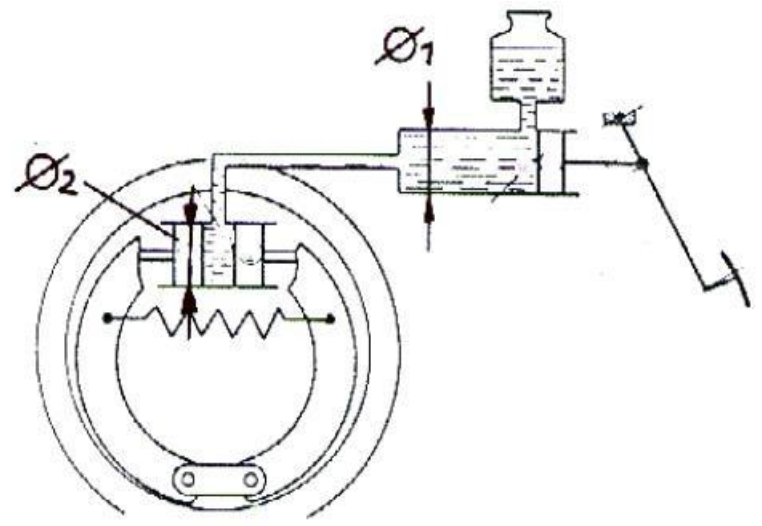


Fig.3: Diameter of the pump and cylinder.

The pressure in the bowls $(\mathrm{Pb})$ is shown in Figure 4, and is calculated as follows:

$\mathrm{Pb}=\mathrm{x}=\mathrm{F} \_2 /\left(\left(\varnothing \_2 \wedge 2 * \pi\right) / 4\right)$

Since $\emptyset_{-}(2$,$) the diameter squared of the wheel plunger$ pushes the shoes against the drum or pads against the disk to cause the wheels to lock.

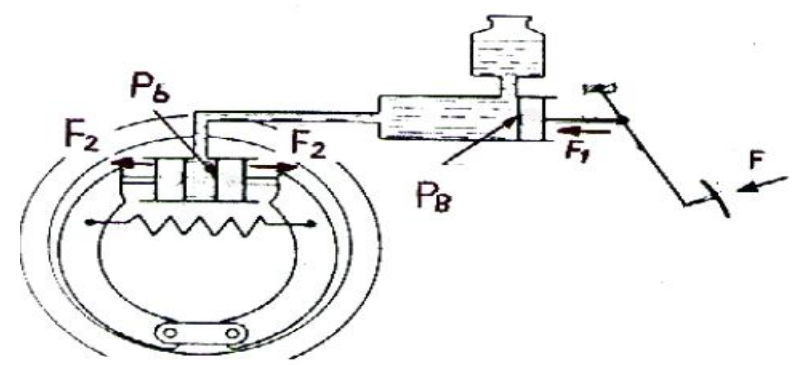

Fig.4: Hydraulic brake circuit.

The F1 force communicated to the rod of the cylinder is amplified by the hydraulic system which is based on the fact that the liquids are not compressed and that according to the law of pascal "The pressure exerted on any point of a liquid mass is transmitted in all directions and directions "The pressure $\mathrm{pB}$ obtained in the main brake pump is equal to the pressure in the wheel bowls and therefore F2 can be calculated:

$\mathrm{F} 2=\left(\mathrm{F}_{-} 1 \wedge * \emptyset_{-} 2^{\wedge} 2\right) /\left(\varnothing_{-} 1 \wedge 2\right)$

Substituting values in equation 4 we have that the pressure $\mathrm{PB}$ or force two is equal to $261.63 \mathrm{~N}$.

$\mathrm{F} 2=((356.66) *(0.01905) \quad 2) /((0.0221996) \quad 2)=$ $262.6358 \mathrm{~N}$

Where the force with which the pistons of the wheel pushes the shoes against the drum F2, is equal to the product of the force F1, obtained in the push rod of the plunger of the brake pump by the diameter $\varnothing \_2$ of the piston of Wheel cylinder squared on the diameter $\emptyset_{-} 1$ of the squirt of the pump squared.

So the force F2 depends a lot on the reaction in the selections of the pistons in the cylinders of the pump and the bowler

\section{Braking time}

Considering the maximum speed of the car is $75 \mathrm{~km} / \mathrm{h}$, with new tires on the normal dry asphalt whose coefficient of adhesion is 0.6 , the time taken to stop the car from the moment the driver observes an obstacle to apply the brakes until the vehicle comes to a complete stop;

$\mathrm{Tp}=\mathrm{v} / \mu * \mathrm{~g}+1$
Substituting values in equation 5, the braking time of the vehicle will be 4.2 seconds.

Calculation of friction forces between braking elements and the friction force between tire-floor.

To know the frictional force between the braking elements (brake pedal and force), it is considered that the driver exerts a pressure of 11 kilograms force therefore the force will be $107.91 \mathrm{~N}$. The friction between the wheel and the floor is due calculate to know the force necessary to stop the vehicle considering that the maximum speed of the car is $75 \mathrm{~km} / \mathrm{h}$.

To calculate the force F1 you get the result of the brake pedal levers on the push rod of the brake pump.

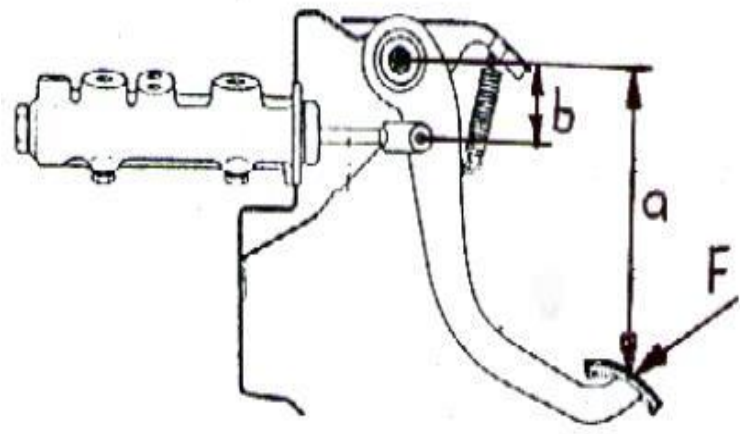

Fig.5: Brake pump

The data to determine F1 are shown in Figure 5.

Data:

$\mathrm{a}=20 \mathrm{~cm}$

$\mathrm{b}=6 \mathrm{~cm}$

$\mathrm{F}=107.91 \mathrm{~N}$

$\mathrm{F} 1=\mathrm{F} * \mathrm{a} / \mathrm{b}$

$\mathrm{F} 1=(107.91 \mathrm{Nm}) /(20 \mathrm{~cm} * 6 \mathrm{~cm})=359.7 \mathrm{~N}$

Substituting values in equation 6 , the force of the rod is $259.7 \mathrm{~N}$ and the latter increased with respect to the force applied by the conductor.

The next step is to calculate F2, which is obtained in the wheel of the later cylinders that are drum type.

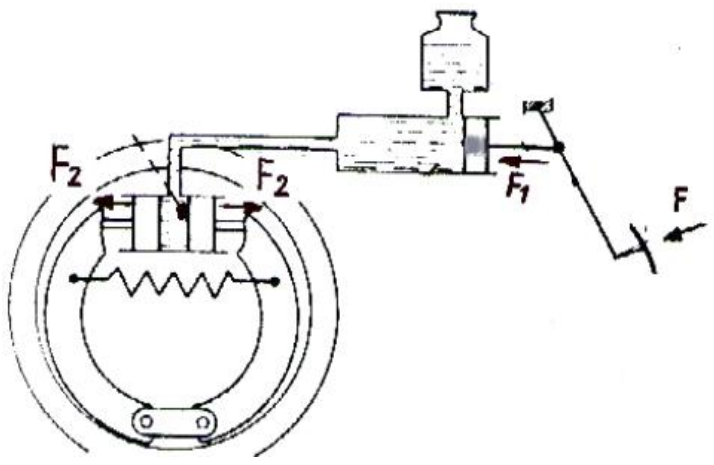

Fig.6: Brakes

$\mathrm{Tp}=(75 * 0.27 \mathrm{~m} / \mathrm{s}) /\left(0.6 * 9.83 \mathrm{~m} / \mathrm{s}^{\wedge} 2\right)+1$ 


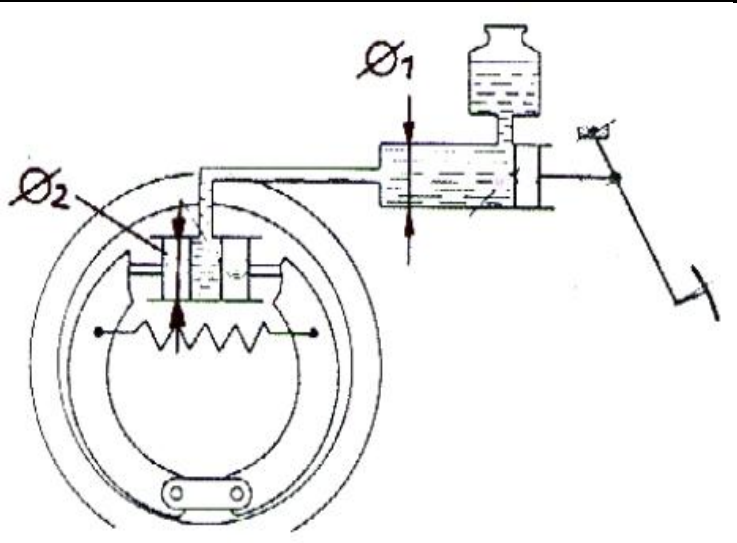

Fig.7: Diameter of the cylinders

In figures 6 and 7, F, F1, F2 are schematized in the brake circuit.

Now we calculate the force that is obtained in the rear wheel cylinders (F2).

$\varnothing 1=2.21996 \mathrm{~cm}$

$\varnothing 2=1.9050 \mathrm{~cm}$

$\mathrm{F} 2=\mathrm{F} 1 * \varnothing 22 / \varnothing 12$

$\mathrm{F} 2=359.7 \mathrm{~N} *(19.05 \mathrm{~mm}) 2 /(22,199) 2$

$\mathrm{F} 2=264.41 \mathrm{~N}$

We also calculate the force F2 that is obtained from the cylinders of the disc-type front wheels:

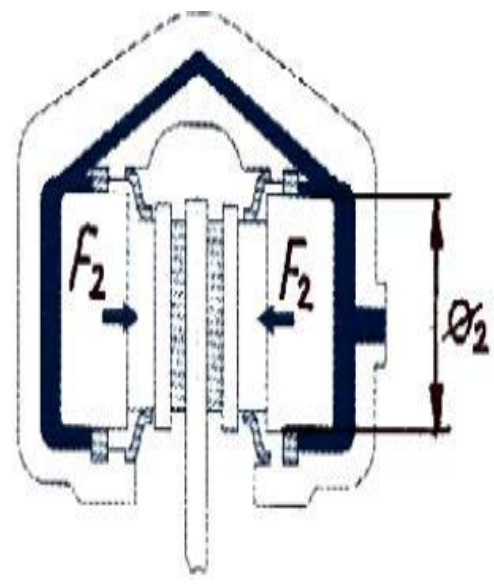

Forces of the disc-type brake pistons

$\emptyset 1=20 \mathrm{~mm}$

$\varnothing 2=52.30 \mathrm{~mm}$

$\mathrm{F} 2=\mathrm{F} 1 * \varnothing 22 / \varnothing 12(7)$

$\mathrm{F} 2=(359.7 \mathrm{~N})(52.30 \mathrm{~mm}) 2 /(20 \mathrm{~mm}) 2$

$\mathrm{F} 2=2459.70 \mathrm{~N}$

We will proceed to calculate the friction between the wheels $\mathrm{Ft}$ for the rear wheels:

Ft back $=$ F 2 back $* \mu$

Ft back $=264 \mathrm{~N} * 0.3=79.2$

We multiply for each back wheel and this would be equal to: $158.4 \mathrm{~N}$.
Then the force of the front tires is calculated with equation 8.

Ft forward $=2479.70 * 0.3=743.91$

We multiply by the number of front wheels and this is equal to: $1487.82 \mathrm{~N}$

For the calculation of the total Fs, the frictional forces of the rear and front wheels $\mathrm{Ft}=\mathrm{Fs} * \mathrm{~d} / \mathrm{d}$ are taken into account

$\mathrm{Ft}=($ Front $\mathrm{Ft}+\mathrm{Ft}$ back $) * \mathrm{~d} / \mathrm{d}$

$\mathrm{Ft}=(158.4+1487.82) 11.3 / 27$

$\mathrm{Ft}=688.97 \mathrm{~N}$

The total friction force ( $\mathrm{Fs}$ ) is $688.97 \mathrm{~N}$, and is equivalent to $107.91 \mathrm{~N}$, which is the minimum force that the driver must apply when operating the brake pedal.

\section{RESULTS}

The braking system with which a Volkswagen sedan is one of the strongest alternatives for the implementation of the prototype, because this brake system meets the needs of drivers in terms of efficiency.

\section{CONCLUSIONS}

The results show that the brakes chosen for the prototype have the ability to stop the vehicle whose maximum speed will be $75 \mathrm{~km} / \mathrm{hr}$.

\section{REFERENCES}

[1] ANDERSON, A. E., (1992). "Friction and wear of automotive brames", Handbook.

[2] AUSIRO B.,\& JORDI., (2005). Puesta a punto y análisis de un banco de pruebas

[3] CARRANZA \& BELTRAN. (2003). "Transferencia de Calor de Estado Inestable

[4] CARSLAW, H.S. AND JAEGER, J.C. (1959). "Conduction of Heat in Solids", 2da de Ing. Indus. de servofrenos para vehículos utilitarios. Tesis Ing Mec., Barcelona, Esc. Tec. Sup. Edición, Ed., Clarendon Press, Oxford. en Forros para Frenos".

[5] KENNEDY, F.E. AND TIAN, X. (1994). The effect of interfacial temperatura on friction and wear of thermoplastics in the thermal control regime, in Dissipative Processes in Tribology, Ed. Elsevier Science, Amsterdam.

[6] RIBBENS, W. B., (2003). Undestanding Automotive Electronics. $6{ }^{\text {a }}$ Ed. Burlington: Newnes. ISBN 0-7506-7599-3

[7] SCHMULLER, J. A., (2001). UML En 24 Horas. $3^{\text {a }}$ Ed. UK: Prentice-Hall, 2001. ISBN: 9-6844-4463-X

[8] SHAMES I. H. (1969). Ingeniería Mecánica Dinámica México, Vol. II Vol. 18, Ed. Blau. 